This is a self-archived - parallel published version of this article in the publication archive of the University of Vaasa. It might differ from the original.

\title{
The Many Faces of Social Withdrawal in Hikikomori
}

Author(s): Kirjavainen, Hanna; Jalonen, Harri

Title: $\quad$ The Many Faces of Social Withdrawal in Hikikomori

Year: $\quad 2020$

Version: Accepted manuscript

Copyright (C) 2020 Springer Nature Switzerland AG. This is a post-peer-review, pre-copyedit version of an article published in Well-Being in the Information Society. Fruits of Respect: 8th International Conference, WIS 2020, Turku, Finland, August 26-27, 2020. The final authenticated version is available online at: http://dx.doi.org/10.1007/978-3-030-57847-3_11

\section{Please cite the original version:}

Kirjavainen, H. \& Jalonen, H. (2020). The Many Faces of Social Withdrawal in Hikikomori. In: Cacace, M., Halonen, R., Li, H., Orrensalo Phuong, T., Li, C., Widén, G. \& Suomi, R. (eds.): Well-Being in the Information Society. Fruits of Respect: 8th International Conference, WIS 2020, Turku, Finland, August 26-27, 2020, 156-168. International Conference on Well-Being in the Information Society, vol 1270. Cham: Springer. https://doi.org/10.1007/978-3-030-57847-3_11 


\title{
The Many Faces of Social Withdrawal in Hikikomori
}

\author{
Hanna Kirjavainen ${ }^{1, *}$ and Harri Jalonen ${ }^{2}$ \\ ${ }^{1}$ Turku University of Applied Sciences, Finland \\ hanna.kirjavainendturkuamk.fi \\ ${ }^{2}$ University of Vaasa, Finland \\ harri.jalonen@univaasa.fi
}

\begin{abstract}
This paper discusses socially withdrawn youths' posts on an internet forum. We explore their situation and ask what are the challenges preventing them to participate into society. We use the capability approach as our viewpoint, wanting to pinpoint the youths' realized capabilities to join in and feel included, as opposed to the opportunities society provides them. Problems with mental health, autism spectrum disorders, social anxieties and frustration towards society were identified as reasons for social withdrawal, indicating that the participants do not feel like their skills and persona is appreciated by the society.
\end{abstract}

Keywords: Social Withdrawal: Social Media: Youth Research

\section{$1 \quad$ Introduction}

Within the so-called vulnerable populations, it is often so that they either use public services excessively or do not utilise them at all. Both cases consist of many dissimilar groups with nothing much in common, but the mismatch between the existing services and the needs of individuals. It is obvious that there is a need to learn more about both groups' preferences, but the methods traditionally used in involvement are not always the most effective ones. Previous research has identified that vulnerable and disadvantaged populations have difficulties to participate due to their difficult conditions or circumstances, lack of skills, poor health, economic situation or power differentials $[1,2]$.

Especially challenging are the "invisible" target groups, who appear to have isolated themselves: residing outside the system, not wanting much from it, even being distrustful towards its fruits. How are the public service providers able to motivate this kind of groups to participate in society and how are the unsatisfying services developed to better match the needs of this kind of groups, if the service providers are not able to reach them and don't know much about their preferences?

One example of these kind of groups is socially withdrawn youths. It is a growing worldwide phenomenon in developed societies, consisting of young people confined in their homes, avoiding social contacts. Social withdrawal is seen as a complex hybrid of social and psychiatric issues as many, but not all, socially withdrawn suffer from psychiatric disorders [3, 4]. There is a lack of research, which could help to understand the nature of this phenomenon and guide future research, policy and practice [5].

Social withdrawal can be seen as a form of social exclusion and not being in education, employment or training (so called NEET youth) raises the risk to withdraw [10]. In Finland, amongst 20-24 years old, there was approximately 38.000 NEET-youths in 2018: $11.8 \%$ of the whole age group [6]. According to research, their experiences of well-being are lower than average, and they feel lonely comparatively often [7].

Technology can bring new forms of participation to public service development, so that also those citizens, who are traditionally unreachable, can access it. So far, this kind of involvement has been quite low. However, particularly social media can be seen as a context for developing the services and co-creating them together with the users. Social media empowers individuals to create and share content that the governance is not able 
to control [8]. This paper takes this viewpoint and approaches social media as a context from which it is possible to derive information, which would otherwise be unattainable.

This paper is part of a larger research in which the aim is to find out, what are the challenges preventing socially withdrawn youths from participation and inclusion, and what would motivate them to "join in". In this paper, the focus will be on theoretical framework and initial findings.

Socially withdrawn people are not easy to research, as they try to avoid human contacts. There is a gap in the research in letting their voice to be heard, as it is not easy to find out their preferences and opinions. Social media can shed a light on socially withdrawn youths' everyday lives. This light helps to understand the situation and challenges of these youths and enriches the public service providers' knowledge about them. Thus, social media is able to make the experiences of the socially withdrawn youths visible.

\section{Theoretical framework}

\subsection{Social Withdrawal and the Hikikomori Syndrome}

Social withdrawal is defined as permanent, solitary behaviour. Socially withdrawn people avoid social interaction and spend more time alone than the age group in general [9]. It is an issue, which can be interpreted both from the psychological and from the societal point of view. Leaning on Husu \& Välimäki $[10,607]$, we define social withdrawal as a "complex set of relationships between self and society", as opposed to viewpoints based solely either on society or individuals' psychological and behavioural features.

The interlinkage between society and withdrawal is visible on earlier research showing that NEET youths feel lonelier than youths studying or working. This might be not only because of fewer contacts to other people, but also because lack of finances, psychological strain and shame $[12,13]$. On the other hand, the NEET status might be caused by health or mental health problems such as depression, which is linked to loneliness. Välimäki et al. [12] propose that having no friends may be even more stigmatizing than not being in employment or in education: more personal and more difficult to get over, especially as youths are expected to live a socially active life. However, studying or working does not guarantee inclusion and on the other hand, NEET youths do not necessarily suffer from social exclusion, as they might have a large social network [11, 12].

Husu \& Välimäki [10] identified three different factors, which explain social withdrawal. First, there are too high expectations from the society, the impossibility of non-educated youths to attain status, income and social capital. Second, individuals have mental health problems and they lack the social skills needed in the society. The third theme overlaps with the previous two as it consists of life-changing life events that one is not able to affect, such as a death in the family or bullying. The cause and the reason are not always clear, e.g. bullying may have a negative effect on social skills, but people with poor social skills may be an easy target for bullies [14]. In addition, parents and family structure seem to have an effect through social learning, family environment and genetics $[14,15]$.

One extreme representation of social withdrawal is the 'Hikikomori syndrome'. While it has originated in Japan, it seems to have grown worldwide [3], spreading with the growth of industrialization and individualism [9], as well as the constant use of technology and social media. The Japanese Ministry of Health, Labour and Welfare has attached five signs to this condition: a young individual who stays mostly at home, has no interest in social activities, continuation of the situation for at least six months, the person does not have a psychotic disorder or a low level of IQ and has no close friends [16]. Having said this, there is variation amongst the severity of the isolation within the group, and it has been suggested that Hikikomoris are able to have "less-demanding" friendships, such as online friends. Typically, Hikikomoris are men, the ratio being four 
men to one woman $[15,16]$.

Many, but not all of the Hikikomoris suffer from mental disorders [15].It is not easy to analyze, when the social withdrawal is merely a symptom of some mental disorder and when it is a primary disorder itself. It has been suggested that the Hikikomori syndrome should be added to the DSM (Diagnostic and Statistical Manual of Mental Disorders) as a new psychiatric disorder [3,4]. However, one has to bear in mind the societal impacts on the Hikikomori phenomenon, as structural marginalization is evidently linked, and even causes social marginalization $[12,13]$.

\subsection{The capability approach to social withdrawal}

The capability approach has become an important framework in relation to well-being in recent decades. Amartya Sen is one of the key developers of this framework. Sen's capability approach focuses on what people are actually able to do and to be, their "functionings", as opposed to their feelings and possessions. He sees the actual opportunities, "capabilities" individuals have, as more important than their income or other material means. "Agency" is another important concept of the capability theory. It means the ability to pursue and to realise the goals one personally wants, no matter what they consist of. The concept is thus wider than well-being; moreover, sometimes a person might even have goals, which go against his/her personal welfare $[17,18,19]$.

Freedoms to "doings and beings" are dependent both on individual and contextual aspects. Surrounding society enables these functionings, both in the level of social and economic institutions and in the level of political and civil rights [20]. Sen addresses poverty as a deprivation of certain crucial capabilities: not just the physical ones, but also more elaborate social achievements, such as taking part in the community or being able to appear in public without feeling shame. This broadens the concept of wellbeing, as quality of life is more than the resources one can access. Social exclusion can be seen both as a part of capability poverty and as a cause of capability failures $[17,18,21$, see critique of Sen's work e.g. 22].

It is important to distinguish Sen's idea of freedom and individual choice from neoliberalism. The neo-liberal viewpoint individualises achievements, whereas Sen takes the diversity of people as his starting point, enhancing the significance of the surrounding society, as the interests depend on available opportunities and resources [23]. Moreover, the capability approach acknowledges the importance of societal structures and institutions [24]. The capability approach can and has been used in empirical studies in a variety of ways, covering wide range of fields. It has acted as an evaluative framework of different aspects of an individual's or group's well-being, as a tool for social cost-benefit analysis or as a viewpoint to evaluate policies [24, 25].

Implementing the capability approach to social exclusion is expedient, albeit not straightforward [26]. Hick [27], for example, states that this is due to the ambiguous and multi-dimensional nature of the social exclusion as a concept. He questions whether social exclusion is an academic concept at all but just rhetoric connected with negative associations without a shared understanding. However, Hick concludes that the capability approach is useful to connect to social exclusion, as it emphasises the multidimensionality of poverty, not just the resources, while acknowledging the material as a side as well. The specific framework should be adapted contextually. Peruzzi [11] states that when based on the capability deprivation approach, social exclusion can be defined as the outcome of diverse interactions between resources and constraints. This process is dynamic in nature, altering the capabilities over time. 
There are different operationalizations of capabilities. Burchard \& Vizard [28] list ten domains of most important capabilities in which inequality manifests itself in Britain. These domains are life, physical security, health, education and learning, standard of living, productive and valued activities, participation, social life, identity, expression and self-respect and legal security. Peruzzi [11], in turn, distinguishes seven domains for social exclusion and matches them with corresponding capabilities. These include physical health, mental well-being, enjoyment of social and family relationships, participation in political life, decent standard of living, access to social services and engagement in productive and valued activities.

\section{$3 \quad$ Research methodology}

One representation of social withdrawal and the social withdrawal phenomenon is a Finnish discussion board called Ylilauta (www.ylilauta.org) and especially one of its forums, called "Hikikomero". Ylilauta is a popular forum with over 5 million visitors, approximately 2 million posts and 32 million readings per month. Ylilauta consists of different kinds of sub-boards or forums, in which the users may discuss different themes, Hikikomero being one of them. The Hikikomero forum is represented as a "peer support group for the depressed and socially excluded". The name is based on the Hikikomori syndrome, but it is also a word play; in Finnish language "hiki" means sweat and "komero" stands for a closet. The forum represents a sub-culture of its own, with a sense of community and where also a multitude of words have been developed. The participants distance themselves from the society with negative characterisations about more sociable people and use terms, which emphasize their own separation from the society [29].

According to Haasio [30], even though the name of the forum is based on the hikikomori-culture, it is not exactly the same phenomenon represented there. There are several similarities however: the life of the forum participants is focused around the computer, social contacts are formed exclusively in forums and through computer games, the virtual world presenting an escape route from dissatisfying non-virtual life. Amongst the forum writers, mental health problems seem to be quite common, and their everyday life is characterized by shyness, the fear of social situations and thus, loneliness. Many of them have been bullied in school. The feeling of otherness and isolation is a kind of self-generating downward spiral. On the other hand, the group is diverse: some of the socially isolated work or study, but still try to avoid other people as much as possible $[29,30]$.

The data we are using in this research are posts written to "Hikikomero" in 2018 and 2019. Since Ylilauta is an anonymous discussion board, it is difficult to gather background information about the participants. In their study, Husu \& Välimäki [10] used the questionnaires the visitors themselves had generated. From these, they found that the participants were mostly male (19 out of 26) and their age was between 20 and 30 , plus and minus a few years. It is of course also a possibility that the participants give false information to the forum. However, these results are in line with Haasio's \& Naka's [31] research, in which they concluded that a large number or writers are between 16 and 30 and almost all of them are men.

The capability approach provides a framework to evaluate well-being. Leaning on previous studies, we hypothesize that the capability of the socially withdrawn youths is significantly lower than in the other groups and that loneliness and social anxiety are common amongst them [e.g. 10]. The process leading to social withdrawal is personal and complex, in which societal, psychological, familial and biological factors are intertwined and interlinked [e.g. 15].

Sen suggests that the capability approach is more a framework for evaluation on individual and societal level than a complete theory. Researchers should not make preemptive lists of capabilities, as different purposes and contexts may need different capability sets. In a similar vein, he refrains from giving exhaustive lists of capabilities or prioritize them. This is partly because of the ambiguity of the terms of well-being and inequality, and partly because of the importance of context [18, 19, 32]. 
We deployed thematic analysis in line with our research purposes, informed with the capability approach, the previous literature about and the aspects of socially isolated. We paid attention to the challenges that may prevent socially withdrawn youth from participating in society. Particularly we were interested in decision-making, working life or studying and different services the social sector and employment office provide. We also explored what would motivate the participants to attend and be involved in these kinds of activities. The analysis was conducted as follows.

In order to familiarize ourselves with the posts, we carried a search with the words "osallistua" (take part, participate, attend, engage in, be involved) and "este" (obstacle, barrier, hindrance, impediment). We found out that constraining the search only to these words excluded too many relevant posts. We learned that the posts about different services, working life and studying contained information about the hindrances and obstacles to their participation as well, so we decided to include commonly used words related to these themes.

Thus, we decided to use the following search words:

- Work/job, profession, salary

- Education, study, university, university of applied sciences

- Employment promoting services, rehabilitative work activity, work experience placement, course, labour market training

- Social office, "Kela" (The Social Insurance Institution of Finland)

- Verb "osallistua" (take part, participate, attend, engage in, be involved)

- Noun "este" (obstacle, barrier, hindrance, impediment)

We went through over 2.000 posts, reading them and choosing the posts, which are relevant to our research questions, having thus found 150 compatible posts. We have collated them according to eleven preliminary categories, which were chosen according to the research questions, earlier previous research findings concerning capability sets and the social withdrawal phenomenon. Some of the codes, namely Employers and the act of seeking a job and Motivational aspects emerged from the data.

The chosen preliminary categories are:

- Mental Health (14 posts)

- Social capabilities ( 9 posts)

- Motivational aspects (22 posts)

- Experiences from the public services (18 posts)

- Practical-level hindrances and obstacles (4 posts)

- The attitudes and responsiveness of the Society (11 posts)

- Employers and the act of seeking a job (18 posts)

- Experiences from working life (21 posts)

- Experiences from Vocational Schools and Universities (10 posts)

- Experiences from Employment promoting services (3 posts)

- Proposals and suggestions (19 posts)

Identified themes were not exclusive as in many cases problems overlapped between many categories, e.g. mental health was an issue presented in many posts. We collated the posts according to their main issue. There were several themes, which emerged from the data. 


\section{$4 \quad$ Findings}

Our thematic analysis resonates with Peruzzi's [11] dimensions, the focus being on mental well-being and autism spectrum disorders, enjoyment of social relationships, access to not only to social but also wider public (social, health, employment, youth) services and engagement in productive and valued activities. These dimensions resonate well with the earlier research. In the following, we present our key findings with real-life examples of the posts posted to the Hikikomero forum.

\section{Mental well-being and autism spectrum disorders}

There were plenty of posts and references to mental health problems and they were present in every category. The importance of mental health does not come as a surprise, considering the close association, previous research has given with loneliness and mental health problems [see e.g. 33]. Several studies point out that loneliness and depression are interrelated with double-sided causality so that depressive symptoms predict loneliness and vice versa [e.g. 34]. This connection might be explained with several similarities between loneliness and depression: they both seem to be related to lowering of social skills, negative cognitive biases and negative experiences from past friendships [35].

In addition, autism spectrum disorders (ASD), especially Asperger and Autism, seem common amongst forum participants. Studies show that youths with Asperger or socalled High-functioning Autism (HFA) have tendency to unsuitable social behaviour and social withdrawal and their quality of life is overall lower than others [36, 37].

Mental health problems and ASDs were interpreted as an obstacle to participate in valued activities, such as working life or studying and go hand in hand with poor social capabilities and lack of motivation. They also seemed to influence how the participants are valued in society, at least their perceptions about this.

"I have fucking severe depression. I always fear that I get stigmatized and then I won't get any job or get any study place, if I go to a head doctor."

"First of all, I am not ashamed of my autism. I have not chosen to have an Asperger syndrome and ADHD linked to that. They are a part of me and connected to certain personality traits and my way of understanding reality. Because it is a neural disorder, I probably do not even understand how autistic I am, but others certainly see it more clearly and probably this fact bothers others more than me. These disorders lead to become a hikky (a noun developed in the forum, meaning a social withdrawn person) not because of shame but because social interaction feels so burdening. One might say that the mind finds peace only in solitude. To become a "hikky" is also heavily affected by that e.g. from workplaces you get fired in a probation period. No one wants to pay from a shitty outcome to an adhd-burger (burger is a noun developed in the forum, meaning a person who does not know how to behave in social situations) if the option is to hire a regular human to do the same job better.

\section{Enjoyment of social relationships}

Low social skills and awkwardness or anxiety in social situations were commonly exclaimed. This might be partly explained by the fact that social skill deficits characterize autism spectrum disorders [38]. Youth with Asperger or High Functioning Autism have the wish to be social, but have lacks in the knowledge of these skills or do not know how to manifest them in social situations. [39, 40]. 
A kind of self-preventive attitude seems also to be a quite commonly shared phenomenon, as low self-esteem and bad experiences from the past block the participants from trying anything anymore. Earlier research has shown that loneliness and depressive symptoms are related to lower self-esteem, as well as ASD's [41].

"(...) I was at work for a while, but I had to quit because of social problems and anxiety. Every day before work I had to take sedatives so that I could be there amongst people, but they stopped working. All the colleagues probably considered me as handicapped, but I guess I am too as I cannot have conversations or eat at the same table as others without my hands shaking and sweat flowing."

"I get many ideas and plans to get back to the course of life, but I don't get even started with any of them, at home there is nevertheless the convenient and familiar everyday life without difficulties, and what if I fail again."

\section{Access to public services}

The experienced exclusion and rejection from workplaces and schools and from the society in general, as well as the incomprehension and belittlement from the service providers, were seen blocking the participants' access to services altogether. Many felt that they have already tried and found that the services are not helping them. One of the explanations might be a gap in services for young people with Asperger or HFA, as they might seem highly functional with their verbal capacities and average or high IQ [40]. Another reason probably is that the Finnish service system is very focused on employment and how to improve one's employability. It does not provide many appropriate options for those with lowered capability to act [42].

"I have received nothing else from the officials, except best verses from the normal people and constant questioning of my own feeling, because nobody can really be with multiple problems, seriously excluded or a wreck with mental health problems. Any real help hasn't been given to me; I have just been pushed coldly to the deep end to learn the noble act of swimming."

"I have complained a lot that I am not capable to work. I did a rehabilitative work in library, but could not be there longer than an hour, because it was too hard. I just started to get unbearably anxious. I was ashamed to go away from there after the first hour."

\section{Engagement in productive and valued activities}

Plenty of discussions revolved around participation in productive activities, as in education, employment promoting services and especially working life. The act of seeking a job was described as depressing. It was seen that employers did not appreciate the participants' skills, or they didn't even get an answer to their job application. Many shared the idea that you have to have the right kind of networks or relatives in order to get a job. Moreover, many participants had several years' gaps in their curriculum vitaes, which they thought prevented them for getting a job.

"I have been trying to get a job, but nobody hires a person, who has wasted 10 years of his life in a University and not even achieved Bachelor's degree. No work, no money. 10 years of life thrown away."

Overall, working life is seen as very severe, with its requirements, competitiveness and demands for social skills. Surprisingly many seemed to have work experience, but it was mainly bad. Bullying and burnouts were mentioned in many posts. Many participants claimed that they are not able to work full hours in current working life, especially if the job is unsatisfactory or the life does not consist of positive elements to counter the work. Internationally, employment rates of those with Autism spectrum disorders seem to be significantly lower. This is unfortunate not only because from the individuals' perspective, but also because people with ASD have many strengths and capabilities useful in jobs with the need of accuracy and precision [37]. 
“(...) I have done grunt work for two years altogether, but you simply just cannot manage the rat race for long, as you don't have any other life besides the work. Couple of times I have also tried to "normalize" myself socially, but those efforts have not been enough, and I had to return to my closet to depress."

The employment promoting services were also a popular topic. The most shared opinion about them seemed to be that they were exploitative and not a valued activity as such. Some of the participants referred to these services as 'slavery' and voiced very pronounced opinions about them. However, some of the participants thought that services were appropriate and provided value. A literature review of customers' experiences from rehabilitative work in Finland, from which many forum participants had experiences, states that the most important development needs customers express are more meaningful tasks and better compensation. Customers' diverse needs do not seem to be taken into account. Very few proceed to "actual" working life, as would be the intent, which probably decreases motivation towards these kind of services [43].

"If you like that idea that someone else rakes in money from your work, who am I to judge anyone's experiences from rehabilitative work. I don't have anything against it, that with 9 euros' "salary" one drinks coffee, solves crosswords and talks crap, but if you get to do real work (even easier ones), my moral says immediately no. It is so that you have to pay decent salary from work, with its benefits and pension accruals, otherwise it is all about slavery, which distorts the appreciation of work and job opportunities e.g. in outdoor work and in the cleaning field."

There were several posts dealing with working life. Many wishes about paid jobs and adjustments of working life were raised.

“(...) That compromising is extremely stressful to an autist. In the long run, anyone tires if he tries to constantly act against his nature. In schools, there are peaceful spaces for those who need them, in workplaces there could also be. Adjusting the working life doesn't require impossibilities (...)"

This all is in line with earlier research about Finnish NEET youths' experiences, which has shown that poorly functioning job market, disappointments and bad experiences from different kind of employment services are common [42]. Youths also wish to have a real compensation from their work. However, the service system does not have much of an impact to the labour market [42]. One option could be e.g. kind of a retirement allowance for those whose actual possibilities to find paid labour is low, and who are willing to commit long-term to some societally important task [43].

\section{Conclusion}

As the number of youths withdrawing to their homes continues to rise [15], there is an urgent need to understand the mindset and experiences of this group. This paper has endeavoured to increase our understanding of socially withdrawn youths' life by mapping out four dimensions, how the social exclusion and social withdrawal are manifesting themselves in the Hikikomero forum participants' life. The results show that social media provides a window to the every-day life of socially withdrawn youths in a way that can be used for enriching the knowledge base of service co-creation processes.

We identified four dimensions, i.e. mental well-being and autism spectrum disorders, enjoyment of social relationships, access to public services and engagement in productive and valued activities. These dimensions are in many ways intertwined and interacting with each other. Low social capabilities, for example, often go hand in hand with mental health problems and long-term disengagement from valued activities usually entails lower mental well-being and social skills. Frustration towards society is common as are the expressions that the participants feel like their skills and persona are worthless in the society. 
Using an online forum as data raises ethical considerations, as the writers have not been able to give consent to participation. The forum is public and there is a disclaimer that the posts may be used as research material. However, some of the writers might not realize that this is the case, as the boundaries between private and public tend not to be so evident in online contexts [44]. We have respected the participants' privacy, not individualizing any writers nor providing any identifiable information about them. The text extracts are translated from Finnish into English, meaning that the data does not exist in the same format in the Internet as it does in this paper.

There are a few limitations to this research. The sample was collected from one Finnish discussion board. In addition, using internet as a data source might lead to unrepresentativeness of the target group. It is obvious that social withdrawal is such a complex phenomenon that it cannot be understood by analysing 150 social media posts. However, Hikikomero and similar social media platforms may provide a unique window into the lives of socially withdrawn youths, although one has to be careful about making adaptation assumptions to other contexts with different cultures. A qualitative research enables to explore the obstacles and also motivations of the participation. More research is definitely needed. One possible avenue for further research would be to examine how the data from social media can be used for developing public services to hard-to-reach people. In addition, it would be worthwhile to explore how artificial intelligence (e.g. unsupervised machine learning techniques) can be harnessed to analyse social media discussions. 


\section{References}

1. De Freitas C, Martin G. (2015). Inclusive public participation in health: policy, practice and theoretical contributions to promote the involvement of marginalised groups in healthcare. Social Sciences \& Medicine. 135, 31-39.

2. Corus, C. \& Saatcioglu, B. (2015). An intersectionality framework for transformative services research, The Service Industries Journal. 35: 7-8, $415-429$.

3. Kato, T.A., Tateno, M., Shinfuku, N., Fujisawa, D., Teo, A.R., Sartorius, N., ... \& Kanba, S. (2012). Does the 'hikikomori' syndrome of social withdrawal exist outside Japan? A preliminary international investigation. Social Psychiatry and Psychiatric Epidemiology. 47, 1061-1075.

4. Teo, A.R., \& Gaw, A.C. (2010). Hikikomori, a Japanese culture-bound syndrome of social withdrawal? A proposal for DSM-5. Journal of Nervous and Mental Disease. 198, 444-449.

5. Li, T.M.H \& Wong, P.W.C. (2015). Editorial Perspective: Pathological social withdrawal during adolescence: a culture-specific or a global phenomenon? The Journal of Child Psychology and Psychiatry. (53, 10), 1039-1041.

6. Valtioneuvosto (2019). Koulutuksen ja työn ulkopuolella olevat (NEET) nuoret, katsaus tilanteeseen ja toimenpiteisiin. [online] https://valtioneuvosto.fi/documents/1410845/4449678/Koulutuksen+ja+ty\%C3\% B6n+ulkopuolella + olevat $+\% 28 \mathrm{NEET} \% 29+$ nuoret $\% 2 \mathrm{C}+$ katsaus + tilanteeseen $+\mathrm{ja}+$ toimenpiteisiin/51231944-1fc0-ef0b-fc7aafc6c975b010/Koulutuksen+ja+ty\%C3\%B6n+ulkopuolella+olevat+\%28NEET\% $29+$ nuoret $\% 2 \mathrm{C}+$ katsaus + tilanteeseen + ja+toimenpiteisiin.pdf. [Accessed 9 April 2020]

7. Aaltonen, S., Kivijärvi, A. \& Myllylä, M. (2019). Työn ja koulutuksen ulkopuolella olevien nuorten aikuisten koettu hyvinvointi. Yhteiskuntapolitiikka. 84: 3, 301-311.

8. Fox, C., Jalonen, H., Baines, S., Bassi, A., Moretti, V. \& Willoughby, M. (2019). Co-creation of Service Innovations in Europe (CoSIE) - White Paper. Reports from Turku University of Applied Sciences 259. https://storage.googleapis.com/turku-amk/2019/06/cosie_whitepaper_2019.pdf [Accessed 18 February 2020].

9. Bowker, J. \& Rubin, K. \& Coplan, R. (2016). Social Withdrawal. Encyclopaedia of Adolescence.

10. Husu, H-M \& Välimäki, V. (2017). Staying inside: social withdrawal of the young, Finnish 'Hikikomori'. Journal of Youth Studies. 20: 5, 605-621.

11. Peruzzi, A. (2014). Understanding Social Exclusion from a Longitudinal Perspective: A Capability-Based Approach. Journal of Human Development and Capabilities. 15: 4, 335-354.

12. Välimäki, V., Kivijärvi, A. \& Aaltonen, S. (2019). The links between structural and social marginalisation - social relations of young Finnish adults not in employment or education. Journal of Youth Studies. 6: 1, 93-117.

13. Dieckhoff, M. \& Gash, V. (2014). Unemployment and social participation. International Journal of Sociology and Social Policy. 35: 1, 2, 67-90. Available: Emerald Insight [Accessed 6 March 2020].

14. Segrin, C., Nevárez, N. \& Arroyo, A. \& Harwood, J. (2012). Family of Origin Environment and Adolescent Bullying Predict Young Adult Loneliness. The Journal of psychology. 146, 119-134.

15. Li, T.M.H., \& Wong, P.W.C. (2015b). Youth social withdrawal behavior (hikikomori): A systematic review of qualitative and quantitative studies. Australian and New Zealand Journal of Psychiatry. 49, 595-609. 
16. Pozza A., Coluccia A., Kato T., Gaetani, M. \& Ferretti, F. (2019) The 'Hikikomori' syndrome: worldwide prevalence and co-occurring major psychiatric disorders: a systematic review and meta-analysis protocol. BMJ Open. 2019;9:e025213.

17. Sen, A. (1984a). The living standard. Oxford Economic Papers. 36, 74-90.

18. Sen, A. (1984b). Rights and capabilities. Resources, Values and Development. Harvard University Press, Cambridge, MA.

19. Sen, A. (1985). Commodities and Capabilities. Amsterdam: North Holland.

20. Walker, C. (2005). Amartya Sen's Capability Approach and Education. Educational Action Research. 13: 1, 103-110.

21. Sen, A. (2000). Social Exclusion: Concept, Application, and Scrutiny. Social Development Papers No. 1, Asian Development Bank.

22. Navarro, V. (2000). Development and Quality of Life: A Critique of Amartya Sen's Development as Freedom. International Journal of Health Services. 30:4, 661-674.

23. Orth,Salais, R., \& Villeneuve, R. (2005). Introduction: Europe and the politics of capabilities. In R. Salais \& R. Villeneuve (Eds.), Europe and the Politics of Capabilities (pp. 1-18). Cambridge: Cambridge University Press.

24. Robeyns, I. (2005). The Capability Approach: A Theoretical Survey. Journal of Human Development. 6: 1, 93-114.

25. Robeyns, I. (2006). The Capability Approach in Practice. The Journal of Political Philosophy. 14: 3, 351-376.

26. Alkire, S. (2005). Why the Capability Approach? Journal of Human Development. 6: 1, 115-135.

27. Hick, R. (2012). The capability approach: insight for a new poverty focus. Journal of social policy.

28. Burchardt, T. \& Vizard, P. (2011). 'Operationalizing' the Capability Approach as a Basis for Equality and Human Rights Monitoring in Twenty-first-century Britain, Journal of Human Development and Capabilities. 12: 1, 91-119.

29. Haasio, A. (2015). Toiseus, tiedontarpeet ja tiedon jakaminen tietoverkon 'pienessä maailmassa': Tutkimus sosiaalisesti vetäytyneiden henkilöiden informaatiokäyttäytymisestä. Tampere: Tampere University. Press.

30. Haasio, A. (2018). Hikikomorit. Helsinki: Avain.

31. Haasio, A. \& Naka, H. (2019). An analysis of information shared on hikikomoris discussion forums. Qualitative and Quantitative Mehods in Libraries (QQML). 8: 4, 509-523.

32. Sen, A. (2004). Capabilities, Lists, and Public Reason: Continuing the Conversation. Feminist Economics. 10: 3, 77-80.

33. Heinrich, L. M., \& Gullone, E. (2006). The clinical significance of loneliness: A literature review. Clinical Psychology Review. 26, 695-718.

34. Vanhalst, J., Klimstra, T. A., Luyckx, K., Scholte, R. H., Engels, R. C., \& Goossens, L. (2012). The interplay of loneliness and depressive symptoms across adolescence: Exploring the role of personality traits. Journal of Youth and Adolescence. 41, 776-787.

35. Spithoven, A. W., Lodder, G. M., Goossens L., et al. (2107). Adolescents' Loneliness and Depression Associated with Friendship Experiences and WellBeing: A Person-Centered Approach. Journal of Youth and Adolescence. 46: 2, 429-441. 
36. Bauminger, N., Shulman, C., \& Agam, G. (2003). Peer interaction and loneliness in high-functioning children with autism. Journal of Autism and Developmental Disorders. 33, 489-507.

37. Scott, M., Milbourn, B., Falkmer, M., Black, M., Bölte, S., Halladay, A., Lerner, M., Taylor, J \& Girdler, S. (2019). Factors impacting employment for people with autism spectrum disorder: A scoping review. Autism. 23: 4, 869-901.

38. American Psychiatric Association (2013). Diagnostic and statistical manual of mental disorders. 5th edition. Arlington, VA: American Psychiatric Association.

39. Myles, B. S., \& Simpson, R. L. (2002). Asperger syndrome: An overview of characteristics. Focus on Autism and Other Developmental Disabilities. 17: 3, 132-137.

40. Stichter, J. P., Herzog, M. J., Visovsky, K. et al. Social Competence Intervention for Youth with Asperger Syndrome and High-functioning Autism: An Initial Investigation. Journal of Autism and Developmental Disorders. 40, 1067-1079.

41. Orth, U., Robins, R. W., \& Roberts, B. W. (2008). Low self-esteem prospectively predicts depression in adolescence and young adulthood. Journal of personality and social psychology. 95: 3, 695-708.

42. Aaltonen, S., Berg., P. \& Ikäheimo, S. (2015). Nuoret luukulla. Kolme näkökulmaa syrjäytymiseen $j a$ nuorten asemaan palvelujärjestelmässä. Nuorisotutkimusverkosto / Nuorisotutkimusseura. Verkkojulkaisuja 84. [online] http://www.nuorisotutkimusseura.fi/images/julkaisuja/nuoretluukulla.pdf

[Accessed 1 June 2020].

43. Sandelin, I. (2014). Kuntouttava työtoiminta asiakkaiden kokemana. Kirjallisuuskatsaus asiakkaiden toiminnalle antamista merkityksistä. Terveyden ja Hyvinvoinnin Laitos työpaperi 8/2014. Tampere: Suomen Yliopistopaino Oy.

44. Convery, I., \& Cox, D. (2012). A Review of Research Ethics in Internet-Based Research. Practitioner Research in Higher Education. 6: 1, 50-57. 
